\title{
Tuberculosis: A Study of 111 Cases in an Area of High Prevalence in the Extreme South of Brazil
}

\author{
Ivo Gomes de Mattos ${ }^{1}$, Marta Osório Ribeiro ${ }^{2}$, \\ Isabel Cristina de O. Netto $^{3}$ \\ and Pedro Alves d'Azevedo ${ }^{4}$
}

\begin{abstract}
${ }^{1}$ Departament of Patology, Microbiology and Imunology sector, Federal University Foundation of Rio Grande (FURG); ${ }^{2}$ Central Biochemestry Laboratory (LACEN) - Secretary of Health; ${ }^{3}$ Department of Medicine, Pneumology sector, Federal University Foundation of Rio Grande (FURG); ${ }^{4}$ Departament Microbiology and Parasitology, Federal Faculty of Medical Sciences Foundation of Porto Alegre (FFFCMPA; Porto Alegre, RS, Brazil
\end{abstract}

\begin{abstract}
Tuberculosis is an increasingly important public health problem in developing countries. We studied 111 tuberculosis patients confirmed by mycobacteria isolation between 1998 and 2000 in Rio Grande, in south Brazil. One-hundred-thirteen pulmonary and extrapulmonary clinical materials were examined through culture by the Ogawa-Kudoh method and through smear examination by the Ziehl-Nielsen or Kinyoun methods. The identification of Mycobacterium tuberculosis was done through the usual phenotypical methods. The proportion method (indirect technique) was used to determine the resistance of isolates. The man/woman ratio was $2.6: 1,75 \%$ were white, and the group had a mean age of $39.7 \pm 12.7$. Risk factors were present in $38.7 \%$ ( 34 men and 9 women, $p=0.2$ ), with a mean age of 35 ( $p=0.002)$; infection by HIV was the most frequent $(28.8 \%)$, followed by alcoholism $(16.2 \%)$ and injected drug use (15.3\%). The frequency of $M$. tuberculosis isolates was $\mathbf{9 9 . 1 \%}$. Pulmonary disease occurred in $88.3 \%$ of the cases, extrapulmonary in $9.9 \%$ and $1.8 \%$ in both. There was an association between extrapulmonary tuberculosis and the presence of risk factors $(p=0.0001)$. Resistance to isoniazid was found in $4 \%$ of the isolates and to isoniazid and rifampin in $2 \%$, all being patients with some risk factors. The profile of tuberculosis in the population of this study followed the pattern described for developing regions of the world.
\end{abstract}

Key Words: Tuberculosis, Mycobacterium tuberculosis, resistance.

Tuberculosis, an infectious disease that can be prevented with effective and low-cost therapy, still accounts for three million deaths a year worldwide and for $25 \%$ of avoidable deaths in developing countries [1]. The history of the natural evolution of this disease shows that the host's ability to develop an effective immune response determines whether exposition to the bacilli will result in infection or disease. The infected members of the community are the source for the tuberculosis cases, which in turn become new sources of infection, adding new infected individuals to the population, completing in this way the disease transmission cycle [1]. Today, detection and quick and effective treatment of new cases are identified as the main factors that can lead to reversion of the natural tuberculosis perpetuation scheme, providing a shorter contagious period, cure of the patient and preventing the appearance of resistant Mycobacterium tuberculosis isolates. Undoubtedly, political, social and economic factors influence the differences in the prevalence of tuberculosis among populations. Our aim was to outline the profile of a population of patients with tuberculosis in the

Received on 21 January 2006; revised 16 May 2006

Address for correspondence: Dr. Pedro Alves d'Azevedo. Sarmento Leite street 245/211 - Porto Alegre, RS, Brazil. Zip code: 90050170. Phone: (55) 51 32248822, r.217; fax: (55) 51 32248822, r.178 E-mail:pedroaze@fffcmpa.tche.br

The Brazilian Journal of Infectious Diseases 2006;10(3):194-198. (C) 2006 by The Brazilian Journal of Infectious Diseases and Contexto Publishing. All rights reserved. city of Rio Grande, an industrial-port city in the extreme south of Brazil, within a regional area of high prevalence of this disease [2], based on demographic data, presence of risk factors, laboratory diagnosis of pulmonary and extrapulmonary forms, frequency of isolation of $M$. tuberculosis strains and drug resistance.

\section{Material and Methods}

We evaluated 111 patients with laboratory diagnosis of tuberculosis confirmed by the isolation of mycobacteria. They were at least 14 years old and were attended at the Tuberculosis Attention Service at the Health Center in Rio Grande or at the AIDS and Clinical Service at the University Hospital of the Federal University Foundation of Rio Grande (FURG) between January 1998 and December 2000. At the Health Center, 68 patients were diagnosed based on the finding of acid-fast bacilli (AFB) in sputum smears. At the University Hospital, the study group consisted of all patients $(n=43)$ with cultures diagnosed with mycobacteria during this period. Onehundred-thirteen pulmonary (sputum specimens and bronchoalveolar lavage) and extrapulmonary (ascitic fluid, pleural fluid, fragments of lymph node and liver biopsy) clinical specimens from 111 patients were examined for microbiological characteristics. Records with data on the sex, age, skin color, occupation, origin, risk factors and previous antituberculous therapy were obtained from interviews and/or from information in the medical records. Acid-fast stains of each clinical material were performed using the Ziehl-Nielsen or Kinyoun methods 
[3]. Ogawa-Kudoh medium [4,5] and Ogawa with thiphene-2carboxylic acid hydrazide (TCH), para-nitro-benzoic acid (PNB) and sodium pyruvate [3] were used for the primary isolation and initial identification of $M$. tuberculosis. The niacin production test was used to confirm the isolation of $M$. tuberculosis [3]. The proportion method, through an indirect technique, was used in order to determine the profile of resistance/susceptibility of the isolates of M. tuberculosis to isoniazid $(\mathrm{H})$ and to rifampin $(\mathrm{R})$ [3,6]. All values were reported as mean $\pm \mathrm{SD}$; percentages were calculated for the categorical variables, establishing a 95\% confidence interval (CI). A bivariate analysis was carried out, using the $\chi^{2}$ test or the proportion test for categorical variables, and the Student ttest, for the continuous variables. Comparisons giving $\mathrm{p}<$ 0.05 were considered significant, using a two-tailed test.

\section{Results}

In the evaluation of the demographic characteristics (Table 1) of the patients, a predominance of men was observed, with a ratio of 2.6: 1 . The mean age was $39.7 \pm 12.7$ years, ranging from 14 to 73 . Eighty percent of the cases were between 20 and 49 years old. The mean age among women was $42.8 \pm 11.3$ years and among men $38.1 \pm 15$ years; this difference was not significant $(p=0.09)$. Most of the patients had jobs that do not require specific qualification or schooling; $95.4 \%$ were urban dwellers, with the majority living in the outskirts. The distribution of risk factors reported for 43 patients is shown in Table 2. There was no relation between gender and risk factors, although the number of men $(\mathrm{n}=34)$ with risk factors was greater than the number of women $(n=9, p=0.2)$. The mean age of the patients with risk factors was $35 \pm 0.4$ and the mean age for those without risk factors was $42.8 \pm 13.2$ years $(p=0.002)$. Twenty-two (19.8\%) of the patients had finished treatment recently or some time before, or were on regular use of antituberculous drugs, 85 (76.6\%) had never been treated, and no information was obtained $4(3.6 \%)$ of the patients. Parallel information from acid-fast stains and bacterial culture of 45 clinical materials from the patients attended at the University Hospital made it possible to analyze the performance of acid-fast stain as a method for early diagnosis of tuberculosis (Table 3). Among the isolated strains, 112 from 110 cases were identified as belonging to the species $M$. tuberculosis; one, from one patient, was found to be a mycobacterium other than M. tuberculosis, later identified as M. avium-intracelullare.

There was pulmonary involvement in $88.3 \%$ of the patients with mycobacteria in sputum or bronchoalveolar lavage samples. The extrapulmonary form of tuberculosis was found in about $10 \%$ of the cases, and the most frequent presentation was tuberculous lymphadenitis. Two patients had involvement of extrapulmonary sites, along with the pulmonary infection, one with superficial lymph node impairment and another with liver involvement (Table 4). The proportion of patients with extrapulmonary tuberculosis that presented risk factors was significantly higher than that of those with the pulmonary form $(90.9 \%$ versus $31.6 \%, p=0.0001$, Table 5$)$. Isolates of $M$. tuberculosis from 100 patients were tested with isoniazid and rifampin; six showed resistance, four to isoniazid and two to both drugs. Among the resistant isolates, four were from patients with a history of irregular previous treatment and the other two from patients with risk factors for tuberculosis (diabetes, alcoholism and prison record).

Table 1. Demographical characteristics of tuberculous patients

\begin{tabular}{lrr}
\hline & \multicolumn{2}{c}{ Patients } \\
\cline { 2 - 3 } Characteristics & N & \% \\
\hline Sex (n=111) & & \\
$\quad$ Male & 80 & 72.1 \\
Female & 31 & 27.9 \\
Colorr(n=108) & & \\
$\quad$ White & 81 & 75.0 \\
Non-white & 27 & 25.0 \\
Age(years) (n=105) & & \\
10-19 & 3 & 2.85 \\
20-29 & 20 & 19.04 \\
30-39 & 32 & 30.47 \\
40-49 & 32 & 30.47 \\
$\quad$ 50 or more & 18 & 17.14 \\
Origin (n=109) & & \\
$\quad$ Urban & 104 & 95.4 \\
Rural & 5 & 4.6 \\
Occupation (n=105) & & \\
$\quad$ Non-qualified & 51 & 48.6 \\
Housework & 19 & 18.1 \\
Unemployed & 21 & 20.0 \\
Pensioner & 9 & 8.6 \\
Student & 5 & 4.7 \\
\hline
\end{tabular}

Table 2. Risk factors for tuberculosis among the patients

\begin{tabular}{lccc}
\hline & \multicolumn{3}{c}{ Patients (n=111) } \\
\cline { 2 - 4 } Risk factors* & $\mathbf{N}$ & $\mathbf{9}$ & $\mathbf{9 5 \%} \mathbf{~ C I}$ \\
\hline Infection by HIV & 32 & 28.8 & $20.6-38.2$ \\
Alcoholism & 18 & 16.2 & $9.9-24.4$ \\
Injected drug user & 17 & 15.3 & $9.2-23.4$ \\
Malnutrition & 10 & 9.0 & $4.4-15.9$ \\
Prison record & 2 & 1.8 & $0.2-6.4$ \\
Diabetes & 2 & 1.8 & $0.2-6.4$ \\
None & 68 & 61.3 & $51.5-70.4$ \\
\hline
\end{tabular}

*24 patients with two or more risk factors. CI = confidence interval. 
Table 3. Acid-fast smear results of tests of the clinical materials that had tuberculososis-positive cultures from patients of the University Hospital of the Federal University Foundation of Rio Grande, Rio Grande do Sul, Brazil

\begin{tabular}{lccc}
\hline & \multicolumn{3}{c}{ Acid-fast smear positive } \\
\cline { 2 - 4 } & $\begin{array}{c}\text { No. clinical } \\
\text { samples }\end{array}$ & $\begin{array}{c}\text { Frequency } \\
\text { (n) }\end{array}$ & $\mathbf{( \% )}$ \\
\hline Sputum & 12 & 10 & 83 \\
Bronchoalveolar & 20 & 06 & 30 \\
$\quad$ lavage & 7 & 3 & 43 \\
Lymph node biopsy & 2 & 0 & 0 \\
Liver biopsy & 1 & 0 & 0 \\
Pleural fluid & 3 & 1 & 33 \\
Ascitic fluid & 45 & 20 & 44 \\
Total sample & & & \\
\hline
\end{tabular}

Table 4. Frequency of tuberculosis forms in relation to the origin of the clinical materials

\begin{tabular}{lrrr}
\hline \multirow{2}{*}{ Tuberculosis forms } & \multicolumn{3}{c}{ Patients } \\
\cline { 2 - 4 } & $\mathbf{N}$ & $\mathbf{\%}$ & $\mathbf{9 5 \%} \mathbf{C I}$ \\
\hline & 98 & 88.3 & $80.8-93.6$ \\
Pulmonary & 79 & 71.2 & $61.8-79.4$ \\
Sputum & 19 & 17.1 & $10.6-25.4$ \\
Bronchoalveolar & & & \\
$\quad$ lavage & 11 & 9.9 & $5.1-17.0$ \\
Extrapulmonary & 7 & 6.3 & $2.6-12.6$ \\
Lymph node biopsy & 2 & 1.8 & $0.2-6.4$ \\
Ascitic fluid & 1 & 0.9 & $0.02-4.9$ \\
$\begin{array}{l}\text { Pleural fluid } \\
\text { Liver biopsy }\end{array}$ & 1 & 0.9 & $0.02-4.9$ \\
Pulmonary and & 2 & 1.8 & \\
$\quad$ extrapulmonary & & & \\
sputum+lymph node & 1 & 0.9 & $0.02-4.9$ \\
$\quad$ biopsy & & & \\
sputum+liver biopsy & 1 & 0.9 & $0.02-4.9$ \\
Total & 111 & 100.0 & \\
\hline
\end{tabular}

$\mathrm{CI}=$ confidence interval

Table 5. Association of risk factors with types of tuberculosis

\begin{tabular}{lccc}
\hline \multirow{2}{*}{ Tuberculosis forms } & \multicolumn{3}{c}{ Risk Factor } \\
\cline { 2 - 4 } & Yes & No & Pvalue \\
& $\%$ (N) & \% (N) & \\
\hline Pulmonary & $31.6(31)$ & $68.4(67)$ & 0.0001 \\
Extrapulmonary & $90.9(10)$ & $9.1(1)$ & \\
Pulmonary+extrapulmonary & $100(2)$ & $0(0)$ & \\
\hline
\end{tabular}

\section{Discussion}

Among the 111 patients with a diagnosis of tuberculosis, there was a predominance of males. Worldwide, there are about $70 \%$ more cases among men than among women; recently it was postulated that a combination of biological and social factors, with differences in behaviors, expectations and activities, is responsible for this difference [7]. It could also be related to the higher frequency of risk factors for tuberculosis among men, a fact also observed in our study. When distribution by age was evaluated, a prevalence of patients between 20 and 49 years old was detected, with no significant difference in the mean age between men and women. These data corroborate the observation that tuberculosis is a disease that affects the individual in the most productive period of his/her life [1]. However, recent studies show a dislocation of tuberculosis incidence from adults in general to the elderly $[8,9]$. The observed higher incidence of whites in relation to non-whites may be a consequence of the profile of the population of this region and not to a racial predisposition toward tuberculosis. On the other hand, the prevalence of tuberculosis among blacks in the world is higher than among whites, especially since the population of the African continent is highly affected by infection by M. tuberculosis, with about 1.5 million new cases a year in sub-Saharan Africa [10]. Possibly, this fact has more to do with socio-economic conditions than with ethnics. However, a study conducted in the U.S.A. by Stead et al. (1997) raised the possibility of a difference in the prevalence of tuberculosis due to racial susceptibility [11]. It is pointed out that special attention should be given to groups with higher disease risk for tuberculosis, especially HIV infected patients, institutionalized individuals, alcoholics, injected drug users, beggars and persons with other diseases for which association with tuberculosis has a high probability [12]. In our study, 38.7\% of the patients presented risk factors, the most frequent being HIV infection, alcoholism and injected drug use, respectively. Patients with risk factors were significantly younger than those without them, which may imply a relation of tuberculosis with the lifestyles among young adults today [13]. In Brazil, Monti identified alcoholism as the second-most-frequent risk factor, preceded only by co-morbidity with HIV [14]. There is concern about the growing prevalence of tuberculosis among injected drug users and among convicts in prisons in Brazil and other countries, this sometimes associated being with co-morbidity due to HIV $[13,14]$. Among the isolates from the patients, a frequency of $99.1 \%$ of $M$. tuberculosis was observed, an observation that validates the use of the initial treatment scheme for tuberculosis recommended by the Surgeon General of Brazil [15].

A predominance of the pulmonary form $(88.3 \%)$ of the disease in relation to the exclusively extrapulmonary forms $(9.9 \%)$ was observed. Studies conducted in Brazil as well as abroad have reported similar results [14,16-18]. Nevertheless, 
other authors have been concerned about the growing number of cases of extrapulmonary tuberculosis, including a report by Court et al. in Havana with a rate of $1.3 \times 10^{5}$ in 1995 and of $1.6 \times 10^{5}$ in 1999 [19]. Extrapulmonary tuberculosis has also been growing in industrialized countries, accounting for $7.6 \%$ in $1962,15 \%$ in 1978 and about $25 \%$ in 1994 [20]. Many reasons for this can be found, such as the appearance of HIV infection, the increasing number of transplanted and consequently immunosuppressed individuals, a high level of suspicion on the part of the physician, and the availability and common use of appropriate diagnostic methods for the extrapulmonary form. It is possible that extrapulmonary involvement is underdiagnosed in Brazil, since in the Basic Health Units the priority for tuberculosis diagnosis is examination of sputum smears[12]. A significant association between extrapulmonary involvement and the presence of risk factors was observed, as all patients, except for one, were co-infected by HIV, similar to what has been found in other studies $[13,20]$. There was a predominance of peripheral tuberculosis lymphadenitis in comparison to each of the other extrapulmonary forms, which was also found in other countries [18,20]. During the last few years, the miliary form has been affecting adults with predisposition factors related mainly to immunosuppression $[16,20]$. The two cases of our study were co-infected by HIV. Smear examination of pulmonary and extrapulmonary materials was responsible for the detection of AFB in 44 of the cases attended at the University Hospital, proving its fundamental role as a simple, low-cost and widely-available method, with good sensitivity for the early diagnosis of tuberculosis, making immediate treatment of the patient possible.

In 19 cases, diagnosis of pulmonary tuberculosis was made by isolation of M. tuberculosis from bronchoalveolar lavage. This procedure was responsible for an increase in diagnosis of $19.4 \%$; it has been seen as a sensitive method for the determination of pulmonary involvement $[2,6]$ in patients from which sputum samples are not available. The performance of the various extrapulmonary materials for the detection of mycobacteria differed; a fragment of a lymph node biopsy gave the best result in our study. In some series, the sensitivity of smear examination and culture of this material was close to $100 \%$ [20]. For the diagnosis of miliary tuberculosis, liver and bone marrow biopsies and blood samples have been known as the most informative materials [19-21]. In the two patients with the miliary form, the isolation of $M$. tuberculosis in liver biopsy fragments permitted the diagnosis. Six percent $t$ of the M. tuberculosis strains were resistant to at least one of the evaluated drugs, $4 \%$ to isoniazid and $2 \%$ to both drugs, characterizing multi-drug resistance. The prevalence of isolated resistance to isoniazid is a universal finding [6]. On the other hand, when there is resistance to rifampin, resistance to isoniazid has probably already been developed, since the initial treatment scheme makes parallel use of both drugs, explaining the appearance of multi-drug resistance. Among the Latin American countries, Brazil with 2,888 cases of tuberculosis studied, showed a prevalence of resistance to isoniazid of $6.3 \%$ and to rifampin of $1.5 \%$, while multi-drug resistance occurred at a proportion of $1.3 \%$, levels considered acceptable by the WHO [6]. Irregular use of the therapeutic scheme has been seen as the main risk factor for the appearance of strains resistant to antituberculous drugs $[1,6]$. However, other factors have been proposed, including alcoholism, previous treatment history, cavitary pulmonary disease, and more recently as a prevalent condition, the lack of sanitary infrastructure in the homes [23]. Among the six patients with resistant isolates, four had made the treatment irregularly, one had diabetes, another was alcoholic and had a prison record; all of them had AFB in the sputum smear, suggesting the presence of tuberculosis bacteria in the pulmonary cavity. These patients lived in the outskirts of the city, without adequate sanitary conditions in their homes, confirming previous findings on the socio-economic context of sick patients with resistant tuberculosis in Brazil, as reported by Kritsky [23]. Finally, we call attention to the unfavorable socio-economic conditions presented by all the patients of this study, which are shared by most of the population of this region. Improvement in the infrastructure is of fundamental importance for the reduction of tuberculosis incidence rate in our area, along with the execution of the control measures recommended by the National Control Program of Tuberculosis of the National Coordination of Sanitary Pneumology of Brazil [15].

\section{Acknowledgements}

We thank the Tuberculosis Attention Service at the Health Center in Rio Grande, in the person of Claudio Recaman, MD, always ready to answer our requests, making this study possible. We also thank Raul Mendoça Sassi, Phd., of the Medical School of the Federal University Foundation of Rio Grande for his priceless help in the data analysis.

\section{References}

1. Ait Khaled N., Enarson D., Billo N. Epidémiologie de la tuberculose et de la résistance aux antituberculeux. Rev Mal Respir 1997; 14:5S8-5S18.

2. Secretaria da Saúde do Rio Grande do Sul. Centro Estadual de Vigilância em Saúde-CEVS. Número de casos das doenças de notificação compulsória por CRS, RS, 2001-2002. Disponível em: http//www.saúde.rs.gov.br [May 2004].

3. David H., Frebaul V.L., Thorel M.F. Méthodes de Laboratoire pour Mycobactériologie Clinique. Paris: Institut Pasteur; 1989.

4. Susemihl M.A.A.M.M., Ferrazolli L., Ueki S.Y.M., et al. Avaliação do método de Ogawa-Kudoh para o cultivo de micobactérias. Rev Bras Patol Clin 1993;29:51-4.

5. Ministério da Saúde do Brasil. Manual de Bacteriologia da Tuberculose e de outras Micobacterioses: Isolamento de Micobactérias. 1993.

6. Pablos-Mendez A., Raviglione M.C., Laszlo A., et al. Global surveillance for antituberculosis-drug resistance, 1994-1997. N Engl J Med 1998;338:1641-9. 
7. Diwan V.K., Thorson A. Sex, gender and tuberculosis. Lancet 1999;353:1000-1.

8. Chaimowicz F. Age transition of tuberculosis incidence and mortality in Brazil. Rev Saúde Publ 2001;35:81-7.

9. Lopes-Pelayo I., Garcia-Martos P., Saldarreaga A., et al. Características de la tuberculosis en pacientes mayores de 65 años en el área sanitaria de Cádiz (España). Rev Méd Chile 2004; $132: 325-30$.

10. Dye C., Scheele S., Dolin P., et al. Global burden of tuberculosis: estimated incidence, prevalence and mortality by country. JAMA 1999;282:677-86.

11. Stead W.W., Senner J.W., Reddick W.T., Lofgren J.P. Racial differences in susceptibility to infection by Mycobacterium tuberculosis. N Engl J Med 1990;332:422-7.

12. Consenso Brasileiro de Tuberculose I -1997. J Bras Pneumol 1998;23:294-342.

13. Castilla J., Gutierrez A., Guerra L., et al. Pulmonary and extrapulmonary tuberculosis at AIDS diagnosis in Spain: epidemiological differences and implications for control. AIDS 1997; $11: 1583-8$.

14. Monti J.F.C. Perfil epidemiológico, clínico e evolutivo da tuberculose na região de Baurú, SP. Rev Soc Bras Med Trop 2000;33:99-100.

15. Ministério da Saúde do Brasil. Manual de Normas para o Controle da Tuberculose-1995. J Pneumol 1997;23:281-93.
16. Melo V.O., Soares D.A., Andrade S.M. Avaliação do programa de controle da tuberculose em Londrina - PR no ano de 1996. Informe Epidemiológico do SUS 1999; $8: 53-62$.

17. Chin D.P., Crane C.M., Diul M.Y., et al. Disseminação de Mycobacterium tuberculosis em uma comunidade: implementando elementos recomendados de controle da tuberculose. JAMA/Brasil 2000;4:3473-9.

18. Geldmacher H., Taube C., Kroeger C., et al. Assessment of Lymph Node Tuberculosis in Northem Germany. Chest 2002; 121:1177-82.

19. Court J.I.S., Sanchez O.P., Yero A.L.A., et al. Tuberculosis en la Ciudad de la Habana, 1995-1999. Rev Saúde Publ 2003;37:326-32.

20. Stelianides S., Belmatoug N., Fantin B. Manifestations et diagnostic de la tuberculose extrapulmonaire. Rev Mal Respir 1997; 14:5S72-5S87.

21. Caymmi A.L.S., Silveira M.A.S., Montal G., Lemos A.C.M. Papel da fibrobroncoscopia no diagnóstico de pacientes com suspeita de tuberculose pulmonar. J Bras Pneumol 2004;30:39-45.

22. Correções no I Consenso Brasileiro de Tuberculose - 1997. J Pneumol 1998;24:345-6.

23. Kritski A.L. Risk factors for multi-resistant acquired tuberculosis. J Pneumol 2003;29:55-6. 